\title{
A Interculturalidade nas opiniões de professores de uma escola indígena de Roraima ${ }^{1}$
}

\author{
Raimundo Nonato Ferreira do Nascimento \\ Universidade Federal do Piauí- UFPI \\ nonatorr.33@gmail.com \\ Marion Teodósio de Quadros \\ Universidade Federal de Pernambuco - UFPE \\ marionteodosio@yahoo.com
}

Resumo: Os debates sobre interculturalidade e educação intercultural, tem sido uma constante nos últimos 20 anos aqui no Brasil. Dentro dos debates sobre educação intercultural destaca-se a educação escolar indígena. Neste artigo, nosso intuito é refletir acerca das opiniões que professores indígenas e não indigenas de uma escola indígena, possuem sobre a interculturalidade a educação intercultural. Para tanto, nos utilizamos de um material recolhido durante o trabalho de campo antropológico realizado nos anos 2011 e 2013 em uma comunidade indígena no estado de Roraima. Os resultados apontam que há uma polifonia relacionada a interculturalidade, bem como a ausência de formação específica e de convivência na comunidade por parte professores não indígenas que atuam nessa escola, como fatores importantes para a ausência de uma educação intercultural. Por outro lado, o professor indígena considera a interculturalidade como ferramenta importante de respeito entre os mundos indígena e o não indígena, $e$ reconhecimento do mundo indigena.

Palavras-chaves: Interculturalidade; educação intercultural; escola indígena; professores.

\begin{abstract}
The debates on interculturality and intercultural education, has been a constant in the last 20 years here in Brazil. Within the discussion on intercultural education, indigenous school education stands out. In this paper, our aim is to reflect on the opinions that indigenous and non-indigenous teachers of an indigenous school have about interculturality and intercultural education. For this, we used material collected during anthropological fieldwork carried out between the years 2011 and 2013 in an indigenous community in the state of Roraima. The results show that there is a polyphony related to interculturality, as well as the absence of specific training and community living by non-indigenous teachers who work in this school, as important factors for the absence of intercultural education. On the other hand, the indigenous teacher considers interculturality as an important tool of respect between the indigenous and non-indigenous worlds, and the recognition of the indigenous world.
\end{abstract}

Keywords: Interculturality, Intercultural education, indigenous school, teachers.

1 Esclarecemos que parte das discussões apresentadas neste artigo, já foram realizadas em Nascimento (2014 2017) e Nascimento, Quadros e Fialho (2016). O que faremos nesse texto é retomar a discussão sobre as concepções de interculturalidade para os professores não indígenas, que foram pouco exploradas, tanto na tese como o artigo mencionado. Tomamos como base, nessa análise, parte do material que ainda não havia sido utilizado. 


\section{Introdução}

A interculturalidade vem sendo utilizada como um conceito, no sistema educativo brasileiro, desde os anos de 1980, ganhando mais visibilidade a partir dos anos de 1990. O conceito se desenvolveu para refletir acerca da interação entre as diversas culturas no contexto pós-colonial, nos países europeus e em alguns países da América Latina ${ }^{2}$. Aqui no Brasil, o termo passou a ser utilizado majoritariamente em relação aos povos indígenas.

Nesse sentido, constituiu-se como um modelo educativo destinado aos povos indígenas brasileiros, denominado Educação Escolar Indígena Específica, Diferenciada, Intercultural e Bilíngue $^{3}$. Pretendemos refletir na extensão desse artigo, sobre interculturalidade e educação intercultural, tendo como interlocutores professores que atuam em uma escola indígena no estado de Roraima e as apropriações que fizeram desses termos.

Esse estado possui uma grande diversidade cultural, incluindo imigrantes de diversos países, migrantes de outros estados, povos indígenas e outras populações tradicionais. De acordo com os dados do IBGE ${ }^{4}$, os povos indígenas representam aproximadamente $10 \%$ da população, ou seja, mais de 40 mil indígenas pertencentes a 11 povos (Makuxi, Wapixana, Sapará, Taurepang, Ingarikó, Patamona, Wai-Wai/Hexkariana, Waimiri-Atroari, Ianomâmi, Sanumá e Yekuana), habitando 32 Terras Indígenas que representam 46,24\% do total da área territorial. A população indígena em idade escolar contava, à época da pesquisa, com 238 escolas, 15.026 alunos matriculados na educação básica e cerca de mil profissionais da educação entre professores, gestores e coordenadores pedagógicos, sendo a grande maioria indígena.

É importante frisar que o Estado de Roraima já vinha atendendo as reivindicações dos professores indígenas em termos de formação. Com isso, foram criados alguns cursos: o magistério indígena parcelado, no final dos anos de 1990, o curso de Licenciatura Intercultural Indígena pelo Instituto Insikiram de Formação Superior Indígena da Universidade Federal de Roraima - UFRR, na década de 2000 e o magistério Tamîkan no Centro Estadual de Formação dos Profissionais da educação de Roraima - CEFORR, no final da década de 2010. Todos estes cursos trabalhavam com a perspectiva da interculturalidade e eram destinados apenas aos professores indígenas ${ }^{5}$.

Nosso intuito é compreender as percepções que seis docentes, sendo um indígena e cinco não indígenas, possuem sobre a interculturalidade e a própria ideia de educação intercultural com a qual vinham trabalhando, na época da pesquisa, em uma escola indígena de Roraima.

É importante assinalar que os professores e professoras não indígenas não recebem, em sua formação, conteúdos relacionados a interculturalidade e educação intercultural. Essa realidade se apresenta na escola selecionada, uma vez que a maioria dos professores e professoras é não indígena, apesar da orientação pactuada entre os povos indígenas, de preferir professores e professoras indígenas. Essa situação, por si só, expressa um ponto de tensão na relação intercultural entre as comunidades indígenas e a sociedade envolvente. Para a lideranças indígenas o fato de não ser indígena e não compreender/conviver com a realidade das comunidades prejudica o processo educativo.

\footnotetext{
2 Segundo Michel Wieviorka (1999), nos EUA predominou o multiculturalismo que ele denominou estilhaçado, com base em ações afirmativas e no politicamente correto, mas sem uma perspectiva de integração entre os diferentes grupos, que diverge da interculturalista por não entender que as culturas estão em diálogo e negociação constante. Na perspectiva multicultural, as culturas podem coexistir sem se comunicar, apenas pela tolerância.

3 Para melhores informações sobre essa proposta educativa, ver os Referenciais curriculares para a educação escolar indígena - RCNEI.

4 Dados do último censo, realizado em 2010.

5 Conforme dados do Departamento de Educação Escolar Indígena (DEEI) da Secretaria de Estado da Educação de Roraima - SECD-RR. Ano base, 2010.
} 
No período da pesquisa, a temática da interculturalidade parecia está restrita às licenciaturas interculturais para indígenas, não sendo discutida em outras licenciaturas. Atualmente, a realidade continua semelhante, são poucas as licenciaturas que trabalham essa temática.

Os dados utilizados nesse artigo foram coletados durante a pesquisa de campo do doutorado ${ }^{6}$ realizada nos anos de 2011 e 2013. O texto está organizado em quatro partes, essa introdução, onde apresentamos o tema e objetivo desse artigo, seguido de algumas concepções de interculturalidade que vem sendo trabalhadas por autores latino americanos e brasileiros, que pontuam como este conceito foi sendo absorvido na educação escolar indígena, para em seguida apresentamos as apropriações (ou opiniões) dos professores sobre tal conceito e, finalmente, evidenciamos algumas considerações.

\section{A interculturalidade na produção latina americana: breves apontamentos}

O tema da interculturalidade tem sido recorrente na produção acadêmica brasileira, não somente no campo da Antropologia ou Ciências Sociais, mas também em outros campos do conhecimento, como a Educação. Como consequência, a partir dos anos de 1980, construiu-se uma considerável bibliografia sobre o tema.

Candau e Russo (2010) apontam que no Brasil e na América Latina como um todo, podemos verificar que a abordagem dessa temática está relacionada, sobretudo, à questão da educação escolar indígena. Laura Selene Mateos Cortés (2011) também assinala que o discurso sobre interculturalidade, produzido originalmente na Europa, em contextos de migração de povos das antigas colônias, ao migrar para a América Latina, foi sendo apropriado predominantemente no campo da educação, mais precisamente no contexto da educação escolar indígena. Esta constatação também é evidenciada por Collet (2001).

Célia Collet (2001), ao situar historicamente o conceito de interculturalidade, ressalta que, a partir dos anos de 1970, os governos passaram a recorrer a propostas de educação intercultural como parte das políticas direcionadas aos grupos étnicos nos países europeus e a escola passou a ser vista como uma instituição fundamental nas políticas voltadas às minorias. Foi somente na década de 1980, que surgiram os primeiros trabalhos teóricos sobre interculturalidade, tendo como base as experiências que vinham sendo desenvolvidas em anos anteriores, na Europa. Aqui no Brasil, segundo a autora, houve um crescimento dessa política nos meios oficiais durante a década de 1990, como uma proposta de educação intercultural para as populações indígenas.

É importante ressaltar que as políticas interculturais direcionadas às minorias étnicas foram construídas sobre conhecimentos oriundos da antropologia, tendo como princípio base a ideia do relativismo cultural e visando romper com as práticas integracionistas e assimilacionistas, pois a principal característica da interculturalidade é o respeito à diferença. Esse respeito aponta para um tratamento igualitário, onde não há uma sobreposição de uma cultura sobre a outra. Neste sentido, "a educação intercultural se baseia, principalmente, na formação de professores, voltada para o respeito à diversidade, e em materiais didáticos que contemplem a pluralidade de culturas" (COLLET, 2001, p.07).

Ao refletir sobre as políticas interculturais destinadas às minorias étnicas, sobretudo à educação intercultural, é preciso fazer uma distinção entre interculturalidade e multiculturalidade, uma vez que são confundidos com frequência (DIETZ, 2012; COLLET, 2001; VIEIRA, 1999).

6 A maior parte desses dados foram analisados em Nascimento $(2014 ; 2017)$. 
Para Célia Collet (2001), o Multicultural se refere a um dado objetivo, à coexistência de diversas culturas, sem, entretanto, enfatizar o aspecto da troca ou da relação, podendo inclusive ser usado como referência em contextos separatistas. Já o intercultural, dá ênfase ao contato e ao diálogo entre culturas, à interação, à interlocução, à reciprocidade e o confronto entre identidade e diferença.

Assim, o termo intercultural aparece como uma noção polêmica, carregada de afetividade e caracterizada por uma grande elasticidade semântica. É, portanto, partindo dessa perspectiva que o prefixo "inter" indica uma relação entre vários elementos diferentes, marcando assim uma reciprocidade mas, ao mesmo tempo, uma separação, uma disjunção.

De acordo com Tubino (s/d), a interculturalidade surge como uma resposta ao esgotamento de um projeto moderno e a crise do eurocentrismo logocêntrico, uma alternativa ético-política, frente ao assimilacionismo homogeneizante dos estados nacionais. E na América Latina, surge como uma resposta à imposição cultural e à incapacidade do estado em lidar, de forma razoável, com os conflitos de identidades. Assim, "el sentido de la interculturalidad es un intento basado en los grandes ideales de la Ilustración, por manejar razonablemente el conflicto de las identidades mediante el ejercicio del diálogo y la negociación entre las partes" (TUBINO, s/d, p. 08).

Hoje, quando falamos em interculturalidade, nos referimos a um ambiente mais amplo. Assim, optar pela interculturalidade é optar por um estado que inclua grupos vulneráveis, pela criação de culturas políticas enraizadas nas culturas de base e pela vigência das cidadanias diferenciadas culturalmente que se reúnem em torno de uma cultura política comum. Ou seja, é optar por justiça distributiva e justiça cultural. Dessa forma, a interculturalidade, enquanto atitude e opção filosófica, sustenta-se de maneira direta na ética do reconhecimento e na hermenêutica do diálogo. (TUBINO, s/d, p.08-09).

Ángel B. Espina Barrio (2006) também enfatiza que a interculturalidade é fundada prioritariamente no diálogo entre as diversas culturas. Este poderá acontecer dentro dos mais variados contextos, seja através dos meios de comunicação de massa ou até mesmo através da arte, da religião e da medicina. No entanto, este deve ser visto como um espaço compartilhado de comunicação onde não há supremacia de uma cultura sobre as outras e nem mesmo uma concorrência, pelo contrário, há uma possibilidade de colaboração, segundo ele,

\begin{abstract}
en el campo de la medicina ya se han dado pasos muy prometedores en la colaboración de diversas culturas, dejando atrás dañinos prejuicios, valorándose, por ejemplo, técnicas chamánicas, practicas orientales e intervenciones psicosomáticas otrora consideradas anticientíficas. También uno de los ámbitos culturales donde mayores progresos pueden darse en el sentido apuntando es en el de la cultura simbólica y el folklore. Fiestas, rituales, vestimentas, musicas, danzas, sirven para dar a conocer pueblos y para valorarlos positivamente o al menos saber de su existencia. Es verdad que muchas veces se cae en simplificaciones y estereotipos, motivados por premios económicos-turísticos, o por una engañosa perspectiva exotista, pero no debe desecharse lo folklore como instrumento tanto de afirmación étnica, como de integración y de contacto intercultural. Pues, ambas realidades no son esencialmente contradictorias; son, como decimos, dos polos dialécticos entre los que se mueven las sociedades (BARRIO, 2006, p.13).
\end{abstract}

Diante do exposto, percebemos que a interculturalidade pode ser vista como um diálogo entre culturas, ou seja, uma interação entre os diferentes, feita de forma recíproca (COLLET, 2001); como caminho para a resolução de conflitos de identidade mediante diálogo e negociação (TUBINO, s/ d); ou como relação de dialógica entre culturas (BARRIO, 2006).

Aqui percebemos que os autores são unânimes ao apresentar a interculturalidade como sendo essa relação recíproca entre as culturas, baseada no diálogo. 
No entanto, surgem alguns questionamentos; em nossa atualidade é possível essa interculturalidade como vem sendo pensada por esses autores? Como as populações indígenas e as minorias étnicas concebem esse conceito? A interculturalidade é um fato ou um projeto a ser realizado? Seria, portanto, esse diálogo realizado de forma recíproca e em pé de igualdade? Como este se efetiva na prática no campo da educação escolar indígena? Estaríamos corretos em afirmar que é uma interação entre grupos étnicos e a sociedade envolvente?

Juan Ansion (2007) nos ajuda a melhor refletir sobre esses questionamentos. Para ele, há duas formas distintas de se ver e pensar a interculturalidade. Entre os que buscam o reconhecimento para sua cultura, alguns consideram que o termo se introduziu como uma política que foi destinada a integrar as culturas subordinadas às culturas hegemônicas através da assimilação. Para estes, a interculturalidade surge como uma ameaça vinculada às políticas de estado que buscam, por esse meio, apaziguar os movimentos étnicos na América latina. Para outros, a interculturalidade é utilizada como sinônimo de identidade cultural que coincide com a necessidade de reforçar, reivindicar e valorizar as tradições ancestrais.

Tubino (s/d) também nos chama a atenção para essa dupla interpretação da interculturalidade. Para ele, o diálogo intercultural tem sido pensado de duas formas: como imagem ideal ou como utopia realizável. Como imagem ideal, é visto como sinônimo de ausência de conflito, ou seja, há uma harmonia absoluta entre os diferentes. Como utopia realizável, é sinônimo de resolução razoável de conflitos, não sendo um estado ideal, mas um processo social que pressupõe decisões e acordos voluntários.

Essa multiplicidade conceitual também é notada no campo da educação escolar indígena, pois ao analisar o Referencial curricular para Educação escolar Indígena (RCNEI), percebemos que o conceito de interculturalidade está relacionado a dois referenciais distintos. O primeiro refere-se à existência real de um contexto intercultural no qual habitam os povos indígenas, e a escola seria o ambiente em que essa relação se concretizaria através da interação entre a cultura "ocidental" e a cultura "indígena". A outra perspectiva apontada no RCNEI se refere à interculturalidade em termos de uma busca, ou seja, um projeto de futuro a ser construído pela escola a partir de alguns princípios tais como, diálogo, relativização do conhecimento, apropriação crítica e participação indígena, ou seja, uma interculturalidade de projeto.

Tubino (2005), ao refletir sobre a educação intercultural e bilíngue como política destinada às comunidades indígenas, nos informa que esta tem causado muitas controvérsias. Entre os indígenas da região amazônica há uma grande simpatia, pois estes são os primeiros a reclamar o reconhecimento da diferença e uma educação que contribua para o fortalecimento de sua identidade, já na região andina há vários setores que veem a educação intercultural como uma educação que discrimina e que reforça o preconceito, e há outros que a consideram como uma estratégia do capitalismo para invisibilizar os problemas sociais. Diante desse impasse, o autor nos convida a refletir sobre que tipo de educação intercultural está sendo oferecida a essas populações e como estamos concebendo o conceito de interculturalidade, se uma interculturalidade funcional ou uma interculturalidade crítica.

A interculturalidade funcional, segundo Tubino, é assumida como estratégia para favorecer uma coesão social onde os grupos socioculturais subalternos são assimilados à cultura hegemônica. Favorecendo um maior diálogo entre os diferentes grupos e estimulando a tolerância mútua. Neste sentido, as relações de poder entre os grupos não são colocadas em questão. Já a interculturalidade crítica, trata de questionar as diferenças e desigualdades que foram construídas ao longo da história entre os diferentes grupos socioculturais; sejam esses grupos, étnico-raciais, de gênero entre outros. Essa perspectiva parte da afirmação de que a interculturalidade aponta a construção de sociedades que possam assumir as diferenças como constitutivas da democracia e sejam capazes de construir relações novas e verdadeiramente igualitárias entre os diferentes grupos, e que de certa forma supõe empoderar aqueles que foram historicamente inferiorizados. 
É, portanto, partindo dessas concepções e tensões, que tentamos compreender o sentido da interculturalidade em uma escola indígena de Roraima. Para tanto, tomamos como base conversas e entrevistas com professores indígenas e não indígenas que estavam atuando nas escolas e comunidades, na época da pesquisa.

\section{O que dizem os professores da escola indígena sobre interculturalidade e educação intercultural.}

Desde os anos de 1990, as comunidades indígenas de Roraima vêm lutando por uma educação que leve em conta suas especificidades. Foi nesse contexto de lutas que surgiu o modelo educacional destinado às populações indígenas, denominado Educação Específica, Diferenciada, Intercultural e Bilíngue, que popularmente ficou conhecido como educação intercultural indígena. A partir de então, as escolas indígenas passaram a adotá-lo.

Em Roraima, esse modelo educativo é defendido e empregado em todas as escolas indígenas. É claro que cada comunidade e escola tem suas próprias formas de organização da educação, haja vista que, um dos princípios destacados nesse modelo educativo é que além de intercultural deve ser comunitário. Por esta razão, as comunidades têm total autonomia para pensar e organizar a proposta pedagógica da escola, de acordo com suas necessidades.

Foi, portanto, seguindo esse princípio de uma educação intercultural e comunitária, que buscamos compreender como os/as professores/as indígenas e não indígenas de uma escola em Roraima se aproximavam e refletiam sobre os conceitos de interculturalidade e educação intercultural indígena. Para tanto, elegemos a escola de uma comunidade indígena de uma região próxima à cidade de Boa Vista, Capital do estado, com grande interação cultural e social com a população não indígena.

A escola situa-se numa comunidade mista, formada de pôr indígenas Macuxi e Wapixana, e concentra uma grande quantidade de pessoas não indígenas sobretudo homens, casados com mulheres indígenas. A comunidade era composta por cerca de 200 moradores, no momento da pesquisa.

A escola atendia do primeiro ao nono ano do ensino fundamental e contava com aproximadamente 100 estudantes e 13 professores. Destes, apenas dois eram indígenas, o professor de língua materna e um professor do terceiro ano, ambos matriculados no Magistério TamîKan. Os demais eram professores não indígenas e não moravam na comunidade.

Em sua rotina diária, os professores não indígenas chegavam à escola às 7:30 da manhã, ministravam suas aulas até às 11:45 e iam embora. Aqueles que trabalhavam à tarde, chegavam às 13:30 e davam aulas até às 17:45, findando suas atividades também não permaneciam na comunidade.

Nos diálogos com esses professores e professoras, percebemos uma diversidade de entendimentos sobre interculturalidade, sendo que alguns pareciam nunca ter ouvido falar desse termo. Um dos professores respondeu que a interculturalidade seria um trabalho voltado para as relações entre as culturas, trabalho esse, que deveria envolver toda a comunidade, através de momentos festivos onde a comunidade pudesse demonstrar suas atividades proporcionando uma troca de experiências, para outro seria uma relação entre as disciplinas, vejamos:

É o trabalho voltado para a cultura, envolvendo tudo o que se tem na comunidade, interculturalidade é isso, voltado para cultura, como a cultura da comunidade a cultura indígena que trabalha. Às vezes a gente sai, não só a escola, mas a comunidade toda, eles convidam a gente para ir lá pra comunidade, apresentar eles lá, aí a comunidade todinha vai, vai fazer parte né, trocar experiências, mostrar aquilo que eles desenvolvem, e isso acontece muito aqui. Às vezes elas vêm pra cá e às vezes essa comunidade vai pra outra 
comunidade, e aí eles apresentam o que eles têm lá, e aqui a gente apresenta o que a gente tem aqui, o intercultural por uma parte é a cultura, a cultura da comunidade, do povo indígena. (Professora 01 [não indígena] grupo de discussão realizado em maio de 2013).

Do meu ponto de vista, e a harmonia e a relação entre todas as disciplinas, e o convívio do que está lhe rodeando (professor 02 [não indígena] conversa realizada em 2013).

Essa interculturalidade, eu não sei se eu estou pensando muito negativo nas coisas. Por exemplo: ano 2011, eu cheguei aqui nesse ano. Foi no mesmo ano que você fez a visita aqui. Eu não me lembro, se foi antes ou foi depois. Mas veio os alunos lá da [escola] SADOQUE, aqui com os meninos, aí teve essa questão, essa troca de cultura, se eu não estou enganado isso é interculturalidade, essa troca de experiências, de culturas diferentes, se misturando ali, a visão de cada um, como se comportam, como vivem, o que faz, o que não faz. E aí, foi um momento muito bom, onde os meninos se divertiram, por um momento aquela barreira caiu, não tinha muralha nenhuma entre eles, estavam iguais ali naquele momento que passaram aquelas 4 horas juntos, e foi uma experiência muito boa (Professor 03 [ não indígena], conversa realizada em 2013).

Na perspectiva da professora 1, a interculturalidade estaria voltada apenas para o fortalecimento da identidade dos Macuxi e dos Wapixana, reciprocamente, seria essa relação interna à comunidade, como um processo de valorização e intercâmbio cultural entre as duas etnias, que deixa de lado a cultura ocidental. Ao pensar a interculturalidade desta perspectiva, a professora parece trazer à tona um debate que Candau (2009) chamou de tensão entre interculturalidade e intraculturalidade, sendo esta última mais apropriada para qualificar a relação entre os grupos internos à comunidade, mencionados por ela.

Quanto ao trabalho com a interculturalidade na escola, os professores são categóricos em dizer que a grande dificuldade para realizar uma educação intercultural está no fato de eles não serem indígenas, não conhecerem a realidade cultural da comunidade e não serem formados para atuar em escolas indígenas:

A gente trabalha só que fica um pouco quebrado o nosso trabalho devido à gente não ter a cultura indígena, a gente procura fazer o máximo que pode, é até mesmo a gente não é professor preparado para atuar nas escolas indígenas a gente vem do ensino regular, então a gente sente essa dificuldade de repassar (Professor 04 [não indígena] grupo de discussão realizado em 2011).

No entanto, o professor 4 afirma que, apesar de não ter uma formação adequada para trabalhar com esse modelo educativo, em seu dia-a-dia na escola procura trabalhar com os conhecimentos culturais da comunidade e os ocidentais, promovendo assim uma interação. $\mathrm{O}$ intuito, segundo ele, é demonstrar que não há apenas uma cultura, mas outras formas de ver e perceber determinadas realidades, que devem ser respeitadas.

Seguindo nessa mesma direção, o professor 5 compreende a interculturalidade como uma relação entre a cultura indígena e a ocidental, que no campo educativo estariam em pé de igualdade, sendo vivenciada cotidianamente, na escola e nas relações comunitárias:

A gente tenta, sempre colocando a cultura dos dois lados, tanto a indígena quanto a não indígena pra gente mostrar que tem a cultura deles, mais que tem outras lá fora, e que todas têm de ser respeitadas ao mesmo tempo. Tanto a daqui quanto a de lá, uma das provas disso é o sete de setembro, que tenta sempre colocar a cultura em primeiro lugar. Tem as tradições deles que tem que ser seguidas, coisas do dia-a-dia deles, a dança, a comida, assim coisa do dia a dia deles, justamente temos que mostrar que não existe só esse mundo aqui, existe outro mundo lá fora, e quando eles saírem daqui eles tem que se adaptar a ele também. Então existe essa grande questão, de estar colocando as duas, a indígena e a não indígena. Como a dança, aqui eles dançam o parixara, mas também eles têm o forró lá fora, tem o sertanejo [...]. Então existe muito isso daí e em questão de conhecimento de língua, também existe, na hora de trabalhar eles sempre colocam, oh! 
A nossa língua em primeiro lugar, é tanto que existe, mas também vamos trabalhar as outras, o português. A nossa língua mesmo, o português aí que é superinteressante, então a gente não trabalha sempre com uma e nem sempre com outra, é sempre meio a meio, sempre fazendo essa mescla, (Professor 05 [[não indígena] grupo de discussão realizado em 2011).

Percebe-se, entretanto, quando este enfatiza essa relação entre culturas, elencando alguns aspectos objetivos, como por exemplo, dança indígena versus dança não indígena, esporte indígena versus não indígena e assim sucessivamente, ele parece estar naturalizando as culturas, não percebendo que os indígenas estão em constante processo de interação com os não indígenas, sendo o forró um dos principais ritmos tocado na comunidade. Assim, se aproxima do que Ansion (2007) ressalta como promoção da essencialização da cultura.

Por outro lado, este professor indica uma preocupação na relação dos indígenas com a sociedade não indígena, o que nos deixa a indagar se ele percebe essa troca mais como adaptação dos indígenas ao mundo não indígena do que ao tratamento das trocas em termos recíprocos. Ao mencionar a adaptação ao mundo não indígena, ele parece nos levar para uma relação de mão única. Assim, também devemos estar atentos aos componentes hegemônicos que podem estar associados à leitura particular de cada professor.

Diferentemente deste, para o professor 4, a interculturalidade é um processo de "mistura cultural", tal situação dá-se em virtude da proximidade da comunidade com a cidade, responsável pelo processo de interligação entre indígenas da comunidade e não indígenas da cidade. Segundo ele, "como a comunidade é muito próxima do município, a cultura fica um pouco misturada, tanto a cultura do branco como a do índio, o branco tá interligado aqui e o índio também com a cidade" (Professor 4 [não indígena], grupo de discussão realizado em setembro de 2011). Essa relação entre a comunidade indígena e da sociedade envolvente, entretanto, não produz alguma síntese que englobe os dois grupos, eles continuam separados, e essa separação é constantemente marcada por situações de preconceito e discriminação em relação à comunidade indígena.

Diferentemente destes professores não indígenas, o professor 6 é um indígena Macuxi e percebe a interculturalidade como sendo uma relação entre dois mundos. Um mundo interior que ele classifica como o mundo indígena e um mundo exterior, o não indígena. Segundo ele, em termos culturais não há como comparar a cultura indígena e a não indígena. Dessa forma, a interculturalidade seria de fundamental importância para a realidade indígena, pois não viria agredir ou desqualificar a cultura local, pelo contrário, na comunidade indígena haveria uma interação entre estes dois mundos, preservando assim a tradição local:

É essa relação do mundo interior com o mundo exterior, na verdade eu refiro a dois mundos assim diferentes, é uma forma de eu tá separando, porque a gente sabe que há essa divisão, em termos de cultura, em ponto nenhum a cultura do não indígena ela se compara com a cultura indígena. Então essa educação, a implantação da educação intercultural ela viria resolver essa relação aí, até porque ela é aplicada de uma forma que não agrediria a cultura a religião, a tradição, na verdade ela manteria essa relação sem agredir esses princípios, e ela é até fundamental para a educação indígena. Acontece que eu não sei se está em processo de discussão, a gente vê que tem na LDB, mas a prática ela sempre tem um peso maior para essa cultura não indígena, não tem esse peso igual pros dois lados, porque a partir do momento que você balanceia aqui as duas culturas aí é o momento de interagir. [...]hoje eu vejo que não existe essa aplicação dessa educação intercultural não sei se é porque a gente não teve pessoas preparadas, formadas e os institutos a gente ver que são novos, os cursos são novos, e essas turmas são turmas novas que estão sendo preparadas agora. Quem sabe se eles vierem depois que essa turma toda começarem a atuar não consiga transformar isso aí, não consigam fazer com que aconteça o que tá escrito lá na LDB, porque na verdade o que está faltando é isso (Professor 06 [indígena] entrevista realizada em 2011). 
Nessa proposta de interculturalidade, além do reconhecimento das diferentes culturas, o professor enfatiza os processos relacionais entre estas, na base do respeito e da convivência democrática, defende que a educação intercultural seja uma forma de mediação entre dois mundos, como uma possibilidade de valorização e respeito frente à diversidade cultural.

Além disso, assinala que, no momento, essa educação intercultural ainda não vem sendo realizada. Mesmo que esteja garantida constitucionalmente, na prática a cultura não indígena sempre tem um peso maior, não havendo ainda uma paridade em termos de valorização cultural.

Essa perspectiva de interculturalidade e educação intercultural defendida pelo professor 6 , se assemelha à proposta de uma interculturalidade crítica, como defende Tubino (2005). Uma interculturalidade que aponte para a construção de uma sociedade que assuma as diferenças culturais como elementos constitutivos das sociedades democráticas, sendo capazes de construir relações igualitárias entre os diferentes grupos sociais. Nesse sentido, coincidimos com FornetBetancourt (2004), quando afirma que a interculturalidade não é um chamado de agora, fruto da difusão de uma moda filosófica. A interculturalidade é uma demanda por justiça cultural que vem se formulando há séculos na história social e intelectual da América Latina.

O professor 6 credita a ausência da educação intercultural à falta de formação dos professores, coadunando-se com os professores não indígenas quando afirma que, na escola da comunidade, a educação intercultural ainda não é possível devido à falta de uma formação específica para este fim. É importante ressaltar que existe formação intercultural para professores indígenas, o que nos leva a crer que o Professor estava se referindo aos professores não indígenas. Isto revela um descompasso dentro da própria escola, uma vez que as atividades propostas pelos professores indígenas, em termos de integração em projetos e atividades interdisciplinares ou extraclasse, não recebem muita adesão. Essa falta de integração pode ser ilustrada pelas reuniões comunitárias, nas quais deveriam ser discutidos todos os problemas da comunidade, inclusive aqueles que envolvem a escola. Os professores não indígenas não participavam dessas reuniões, alegando que as reuniões com os pais deveriam ser na escola.

Como vimos acima, a interculturalidade parecia um assunto novo para os professores não indígenas. Além disso, todos os professores da escola possuíam visões bem distintas sobre interculturalidade. Para a professora 1, é um processo de intercâmbio cultural entre as comunidades indígenas, sem levar em conta a relação que se estabelece com o conhecimento ocidental. Já para o professor 2, é a relação entre as disciplinas, ou seja, a interdisciplinaridade. $\mathrm{O}$ professor 3 vai assinalar a troca de experiências entre diferentes culturas, comportamentos e práticas, sendo essa troca baseada na convivência e nos encontros e espaços onde não há conflitos. O professor 4 a percebe como uma "mistura cultural". Para o professor 5, a interculturalidade é vista como uma relação entre culturas, no entanto esta última é percebida como algo estático. Finalmente, o professor 6 destaca a relação entre os dois mundos, o mundo indígena e o não indígena.

Por não possuírem uma formação, ou um curso de aperfeiçoamento, os professores vêm trabalhando de acordo com suas convicções. Por outro lado, o professor indígena apresenta uma concepção bem distinta de interculturalidade daquelas apresentadas pelos não indígenas. Dessa forma, cada professor torna-se responsável por sua compreensão do que seja interculturalidade, sua transposição para a educação escolar indígena e aplicação na escola da comunidade. Nesse sentido, a escola não consegue construir uma orientação pedagógica que proporcione a vivência interculturalidade, mas práticas diversificadas e com lógicas distintas quanto a relação entre os conhecimentos e os grupos em questão. 


\section{Considerações finais}

Ao longo desse artigo, pontuamos algumas ideias e percepções sobre interculturalidade que refletem uma polifonia a acerca deste discurso. Esta polifonia, mais uma vez, vem corroborar o que já afirmamos anteriormente que o discurso acerca do intercultural se constrói dependo do contexto local e histórico.

No conjunto das ideias sobre interculturalidade analisadas, percebemos que os professores 1, 2 e 3 não fazem uma relação evidente entre as comunidades indígenas e a sociedade envolvente, não mencionam conflitos ou tensões entre os grupos referidos, nem relações de poder. Um dos professores, inclusive, restringe a interculturalidade ao espaço escolar. Nesse sentido, esses professores não indígenas se aproximam de uma interculturalidade funcional. Já nos casos dos professores 4 e 5, é possível notar processos de estereotipação como elementos constituintes dessa relação, ainda no plano da interculturalidade funcional. Apenas o professor 6 estabelece diálogo entre os indígenas e o não indígena, deixando evidente a relação de poder existente entre eles.

Essa realidade de múltiplas interpretações apresentada pelos professores e professora, nos aponta para algumas questões que merecem ser refletidas. Ora, entendemos que essa diversidade de interpretações é enriquecedora e necessária para a construção do conhecimento, no entanto, quando se trata de uma política pública, a falta de uma definição mais clara e unificada dos termos centrais da política de educação escolar indígena nos documentos de referência (RCNEI, Diretrizes Curriculares Nacionais para a Educação Escolar Indígena) pode trazer alguns prejuízos à execução da mesma. São raros os documentos oficiais que trazem uma definição ou mesmo uma problematização de determinados conceitos, como cultura, tradição, diversidade cultural e interculturalidade (PALADINO; ALMEIDA, 2012). O próprio RCNEI, que tem como objetivo ser um documento básico para o trabalho dos professores indígenas, define interculturalidade de duas maneiras diferentes.

Ao destacar que essa multiplicidade de interpretações acerca da interculturalidade, por parte dos professores dessa escola, parece ser um reflexo tanto dessa frouxidão conceitual, quando da falta de uma formação específica por parte dos mesmos, não estamos propondo uma unificação dos discursos acerca da interculturalidade e/ou educação intercultural. No caso específico da escola em foco, entendemos que essa polifonia apresentada pelos professores acerca dos adjetivos dados a interculturalidade é de grande importância no fazer pedagógico da escola. No entanto, é necessário que se chegue a um consenso por parte dos mesmos, a fim de que se possam definir princípios norteadores da prática pedagógica.

O debate acerca das apropriações e reflexões de professores e professora não se esgota aqui, mas sugere que essas questões ou essas divergências devem ser analisadas, não somente a partir do ponto de vista do conhecimento eurocêntrico, mas também a partir da visão das comunidades indígenas e das minorias étnicas, que são os destinatários dessas políticas.

Esses dois mundos, que o professor 6 considera incomparáveis, colocam em relação o "conhecimento científico" pretensamente universal e o "conhecimento tradicional particular". Mesmo com toda a multiplicidade de discursos sobre interculturalidade, destacando esta como relações entre culturas e diálogo de saberes, foi possível notar uma hierarquia entre os conhecimentos sendo o conhecimento local visto como tradicional ou originário, colocado em um patamar diferente ou desprestigiado. Esse conhecimento parece estar em busca de sua aceitação e, por isso, necessitar constantemente de uma revalidação do conhecimento científico. Dentro dessa perspectiva, o conhecimento tradicional é considerado, pelo senso comum e por alguns professores e professoras, como estático, ao qual nada deve ser acrescentado, um acervo fechado transmitido por antepassados, um conjunto acabado que se deve preservar, como assinalou Manuela Carneiro da Cunha (2009, p.302) ao enfatizar o equívoco desse tipo de pensamento, pois "o conhecimento tradicional consiste tanto ou mais em seus processos de in- 
vestigação quanto nos acervos já prontos transmitidos pelas gerações anteriores". As hierarquiazações entre esses conhecimentos ou a desvalorização dos saberes locais expressam as desigualdades socioculturais e as dificuldades em alcançar as trocas entre grupos e conhecimentos, portanto, de alcançar a interculturalidade. Concordamos com a autora (CUNHA, 2009, p. 302) quando ela afirma que tanto o conhecimento tradicional quanto o científico deveriam ser entendidos como "formas de procurar entender e agir sobre o mundo", sendo, portanto, "obras abertas, inacabadas, se fazendo constantemente".

\section{Referências Bibliográficas}

ANSION, Juan. La interculturalidad y los desafíos de una nueva forma de ciudadanía. In: Educar en ciudadanía intercultural. Fondo editorial de la Pontificia Universidad Católica del Perú. Lima, 2007.

BARRIO, Ángel B. Espina. Culturas locales iberoamericanas, comunicación e interculturalidad. In: Conocimiento local, comunicación e interculturalidad. Angel B. Espina Barrio (org) Recife: Massangana, 2006.

BRASIL, Secretaria de Educação Fundamental. Referencial Curricular Nacional para Escolas Indígenas. Brasília: Ministério da Educação e do Desporto, 1998.

COLLET, Celia Leticia Gouvêa. "Quero progresso sendo índio". O princípio da interculturalidade na educação escolar indígena. Dissertação de Mestrado em antropologia social. Rio de Janeiro: PPGAS/MN/UFRJ. 2001

CANDAU, Vera Maria. (Org.) Educação intercultural na América Latina: entre concepções, tensões e propostas. Rio de Janeiro 7letras, 2009.

CANDAU, Vera Maria, RUSSO, Kelly. Interculturalidade e Educação na América Latina: uma construção plural, original e complexa. In: Revista Diálogo educacional. Vol.10, n 29, enero-abril, 2010, pp.151-169. PUC-Paraná

CUNHA, Manuela Carneiro. Cultura com aspas e outros ensaios. São Paulo, 2009.

FORNET-BETANCOURT, Raúl. Interculturalidade: críticas, diálogo e perspectivas. São Leopoldo: Nova Harmonia, 2004.

DIETZ, G. Multiculturalismo, interculturalidad y diversidad en educación: Una aproximación antropológica. México: FCE, 2012.

MATEOS CORTÉS, Laura Selene. La migración transnacional del discurso intercultural: Su incorporación, apropiación y resignificación por actores educativos en Veracruz, México. Ediciones Abya-Yala Quito, Ecuador 2011.

NASCIMENTO, Raimundo Nonato Ferreira; QUADROS, Marion Teodósio; FIALHO, Vânia. Interculturalidade enquanto prática na educação escolar indígena. Revista Anthropológicas (on line), v. 27, p. 187-217, 2016.

NASCIMENTO, Raimundo Nonato Ferreira do. Interculturalidade e educação escolar indígena e Roraima: da normatização à prática cotidiana. Tese de doutorado em Antropologia. Recife, 2014. 
Appris, 2017.

Antropologia, interculturalidade e educação escolar indígena em Roraima. Curitiba,

PALADINO, Mariana. ALMEIDA, Nino Paiva. Entre a diversidade e a desigualdade: uma análise das políticas públicas para a educação escolar indígena no Brasil nos governos Lula. Rio de Janeiro: Contra Capa Livraria; LACED/Museu Nacional/UFRJ, 2012.

TUBINO, Fidel Arias-Schreiber. Interculturalizando el Multiculturalismo. In: Biubliotheque de la Méditerranée, Sciences humaines en Méditerranée. s/d. Disponivel em : http://ccr6.pgr.mpf.gov.br/institucional/eventos/docs_eventos/fidel tubino.pdf

.La interculturalidad Crítica como proyecto Ético Político: In: encuentro continental de educadores Agostinos. Lima Peru 2005 . Dis ponível e m : http://oala.villanova.edu/congresos/educacion/lima-ponen-02.html.

VIEIRA, Ricardo. Da multiculturalidade à educação intercultural. A antropologia da educação na formação de professores. Educação Sociedade e Culturas, nº 12, 1999.

WIEVIORKA, Michel. Será que o multiculturalismo é resposta? Educação, Sociedade e Culturas, $\mathrm{n}^{\circ}$ 12. 1999. 